\title{
AN UPDATE ON BIO-POTENTIATION OF DRUGS USING NATURAL OPTIONS
}

\author{
VASUNDHARA SAXENA, AYUSHI SINGH \\ Department of Pharmacy, Ram-Eesh Institute of Vocational and Technical Education, 3, Knowledge Park 1, Greater Noida, Uttar Pradesh, \\ India. Email: singhayushi903@gmail.com
}

Received: 26 June 2020, Revised and Accepted: 05 September 2020

\section{ABSTRACT}

The objective of this review is to put a light on the benefits of bio-enhancers and their role in developing a proper drug delivery system having improved therapeutic action and least drawbacks.

As medical science is developing fast and there is a considerable increase in the development of new drugs with many therapeutic activities, but having lots of side effects, less in vivo action, or are very costly. These drawbacks create an enormous demand for use of bio-enhancers to reduce the dose required of the active ingredients and provide a suitable condition for their actions. There are vast nature-derived bio-enhancers originated from plants or other natural sources, used to a great extent as they show high activity and have very little or no adverse effects. Bio-enhancers increase bioavailability in various ways such as by increasing drug absorption, decreasing drug metabolism, and by other methods, which helps the drug having low bioavailability but the good therapeutic potential to show its effect fast. The concept of bio-enhancers developing increasingly in modern medicine but in reality, was there and well explained in Ayurveda texts with various herbal drugs such as piperine, quercetin, genistein, naringin and some non-herbal compounds such as cow urine distillate, and Capmul.

Along with these nature-derived bio-enhancers and the new techniques such as liposomes, nanoparticles, transferosomes, and ethosomes resulted in the successful modification of suitable dosage forms.

The concept of bioenhancers and their application is a great tool which can lead to a excellent development of medical science.

Keywords: Bioavailability, Bio-enhancers, Ayurveda, Herbal, Medicinal plants, Silver and gold nanoparticles.

(C) 2020 The Authors. Published by Innovare Academic Sciences Pvt Ltd. This is an open access article under the CC BY license (http://creativecommons. org/licenses/by/4. 0/) DOI: http://dx.doi.org/10.22159/ajpcr.2020.v13i11.38889

\section{INTRODUCTION}

Bio-enhancers or bioavailability enhancers are the substances that at a specific dose does not have their activity, still they increase the bioavailability and bio-efficacy of active elements combined with them. In addition to various classes of drugs, they can also increase the bioavailability of vitamins and nutrients [1]. Now talking about bioavailability, it is the fraction of an administered drug that reaches the systemic circulation. Increased bioavailability means increased levels of the active pharmaceutical ingredient within the bloodstream available for drug action.

\section{Role of bio-enhancers}

As the bioavailability increases with these the drug required is a smaller amount; hence, the dose and price of practicing medicine are often reduced, which makes the formulation cost-effective, safer, better tolerated, more efficient, better compliance, and having fewer chances of drug resistance development, for example, as in case of antibiotics.

Therefore, the benefits of adding bio-enhancers:

- Reduced dosage

- Reduced drug cost

- Reduces drug resistance

- Reduces the adverse effects of drug

- Increases drug efficacy.

\section{HISTORY}

The concept of bio-enhancers first introduced in Ayurveda, which was proved by scientist Dr. C. K. Atal at the Indian Institute of Integrative medicine, Jammu, in the year of 1979 and then he coined the term bioavailability enhancers. He got the clue during his research on traditional medicinal drugs mentioned in Ayurveda. In the studies, he noticed that most of the Ayurvedic preparations contained Trikatu, which had three ingredients that were black pepper (Piper nigrum), long pepper (Piper longum), and ginger (Zingiber officinale). Alternatively, one component of Trikatu that was $P$. longum was increasing the bioavailability of many drugs [2]. Following his experimental results piperine (the active part of $P$. longum), the world's first bio-enhancer was derived, which experimented with Sparteine and Vasicine, which became the world's first experimentally bio-enhanced drugs. Later on, many bio-enhancers were discovered [3].

\section{METHODS OF ENHANCING BIOAVAILABILITY}

By increasing absorption

There are various agents such as bile salts, surfactants, and fatty acids which can act as chelating agents, salicylates, polymers, etc., and increases the speed of absorption [4,5]. Chitosan, especially trimethylated chitosan, enhances the absorption by way of the paracellular route by redistributing the cytoskeletal F-actin, which leads to the opening of the tight junctions. Bile, bile salts, and fatty acids are surfactants which act as absorption enhancers by increasing the solubility of hydrophobic drugs within the aqueous layer or by increasing the fluidity of the apical and basolateral membranes. Calcium chelators such as ethylene glycol tetraacetic acid and ethylenediamine tetraacetic acid enhance absorption by reducing the extracellular calcium concentration, resulting in the disruption of cell-cell contact [6].

\section{By making prodrugs}

A medication or compound that, after administration, is metabolized into a pharmacologically active drug is called a prodrug. Taking the example of ampicillin, that because of its hydrophilic nature is merely absorbed $30 \%-40 \%$ from the digestive tract. The carboxyl group of ampicillin is esterified to prepare prodrugs of ampicillin such as pivampicillin, bacampicillin, and talampicillin which are absorbed well, and convert into active ampicillin after metabolism [2].

\section{Pharmaceutical approaches}

There are various formulations and dosage forms, which may help increase the bioavailability such as liposomes and emulsions or 
different techniques of reducing particle size such as nanoparticle creation, micronization, and complexation assist in the absorption of insoluble drugs or can increase the absorption rate $[7,8]$.

\section{Inhibiting the P-glycoprotein}

These are some absorption barriers present on the gastrointestinal tract (GIT) epithelial layer; by inhibiting these barriers, the absorption rate can increase to an excellent extent. P-glycoprotein inhibitors influence the metabolism, absorption, distribution, and elimination of P-glycoprotein substrates in the process of modulating pharmacokinetics [9].

\section{Mechanism of bioenhancers}

Some of the mechanisms of action of bio-enhancers are:

a. Decrease in the secretion of hydrochloric acid and an increase in gastrointestinal blood supply [10]

b. Increasing the stay of what we eat in the GIT so that it has more time to get absorbed. By decreasing the intestinal motility and enhancing the time of stomach emptying [11,12],

c. Modifications in GIT epithelial cell membrane permeability [13,14],

d. Cholagogous effect (increased bile secretion) [13],

e. Bioenergetics and thermogenic properties $[13,15]$ and

f. Stopping the first-pass metabolism, metabolizing enzymes inhibition, and stimulation of gamma-glutamyl transpeptidase activity, intensify the uptake of amino acids $[15,16]$.

For example, mechanism of action of piperine: DNA receptor binding, modulation of cell signal transduction and inhibition of drug efflux pump, etc. [11].

\section{Classification}

Based on origin bio-enhancers can be classified as

1. Herbal origin: They are derived from natural sources, for example, piperine, curcumin, ginger, and caraway .

2. Non-herbal origin: These are bio-enhancers, which are not, obtained from plants but by some synthetic modification of other natural sources, for example, Capmul that is mono-, di- and triglyceride, formulated by the glycerolysis of selected fats, vegetable oils or by glycerin esterification with particular fatty acids; and cow urine distillate $[17,18]$.

Based on mode of toxic action (MOA) - based on MOA classification is as follows

1. Inhibitors of PGPefflux pump: Caraway, quercetin, naringin, and cumin.

2. Suppressor of CYP 450 enzyme and its isoenzymes: Gallic acid and its esters.

3. Regulate GIT absorption: Aloe vera, glycyrrhiza, etc. [19].

\section{Natural product used as bioavailability enhancers}

Quercetin

It is an aglycone form of several flavonoid glycosides found in various citrus fruits. The chemical structure consisting of a chromene ring with a dihydroxy phenol.

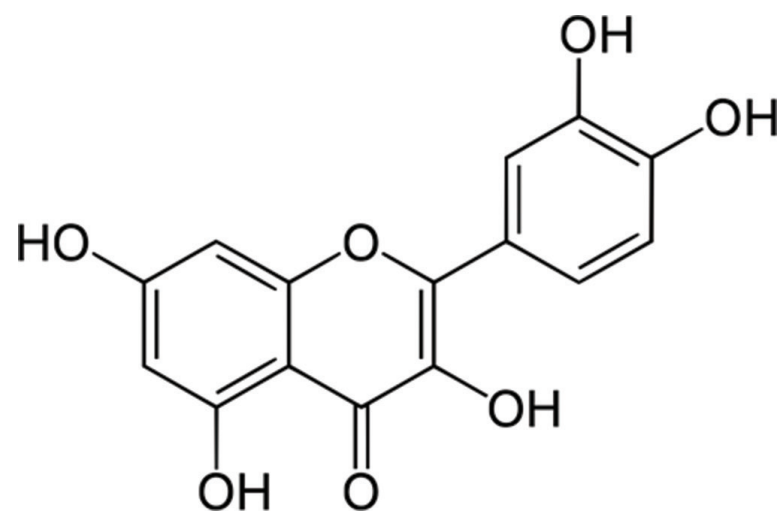

IUPAC name: 2-(3, 4-dihydroxyphenyl)-3, 5, 7-trihydroxy-4Hchromen-4-one
A considerable amount of it is found in apples, raspberries, honey, cherries, onions, red grapes, citrus fruits, green leafy vegetables, etc. Among vegetables and fruits, quercetin content is highest in onions [20]. The wide range of beneficial biological activities shown by quercetin includes antioxidant, radical scavenging, anti-inflammatory, antiatherosclerotic, anti-tumoral, and anti-viral effects [21]. The different examples of drugs such as diltiazem, digoxin, and epigallocatechin gallate had shown a rise in bioavailability, blood levels, and efficacy when used in combination with quercetin [22]

Various preclinical trials showed the ability of quercetin to enhance bioavailability. A preclinical test done on rabbits with diltiazem indicated that the area under the plasma concentration-time curve (area under curve [AUC]) and peak concentration (Cmax) of diltiazem in the quercetin pretreated rabbits were notably higher than those acquired from the groups not treated with quercetin. Various studies describe that diltiazem is metabolized both in the liver and small intestine by CYP3A4. The P-glycoprotein efflux pump prevents the absorption of diltiazem through the mucosa of the intestine. The rise in AUC and Cmax of diltiazem by pretreatment of quercetin might have caused by the inhibition of the P-glycoprotein efflux pump and the metabolizing enzyme CYP3A4 in the intestinal mucosa [23,24].

The reported results are: The absorption of epigallocatechin gallate reported to be enhanced with red onion supplementation, abundant source of quercetin. For $6 \mathrm{~h}$, the AUC of epigallocatechin gallate was increased from 1323 to $1814 \mathrm{ng} / \mathrm{mL}$, when administered along with quercetin. When quercetin was taken along with epigallocatechin gallate, it results in an increased absorption of epigallocatechin gallate from the intestine [25]. The increased bioavailability of moxidectin in lambs was observed due to natural flavonoid quercetin. It was found in various studies that, quercetin was able to modify the pharmacokinetics of moxidectin in plasma of lambs [22]. Oral bioavailability of rivastigmine increased with quercetin nanoparticles due to inhibition of CYP3A4 and esterases [26].

\section{Genistein}

It belongs to the isoflavone class of flavonoids and a phytoestrogen. It is found in numerous plants including lupin, soybeans, fava beans, kudzu, and psoralea being the essential food source, likewise in the medicinal plants, Flemingia vestita and Flemingia macrophylla, and coffee [27]. It consists of a chromene ring.<smiles>O=c1c(-c2ccc(O)cc2)coc2cc(O)cc(O)c12</smiles>

IUPAC name: 5,7-Dihydroxy-3-(4-hydroxyphenyl)chromen-4-one

According to reports, it can inhibit P-glycoprotein, breast cancer resistance protein (BCRP) and multidrug resistance-associated protein 2 (MRP2) efflux function, the intestinal absorption of paclitaxel (a substrate for efflux transports such as P-glycoprotein, BCRP and MRP2) increases dramatically, when co-administered with genistein [28-30]. The contributor in the improvement of systemic exposure of paclitaxel is the inhibition of the efflux transporters caused by genistein. $10 \mathrm{mg} / \mathrm{kg}$ of genistein caused enlargement of $54.7 \%$ in AUC and a decline of $35.2 \%$ in the total plasma clearance after oral administration of paclitaxel at an amount of $30 \mathrm{mg} / \mathrm{kg}$ in rats [30].

\section{Naringin}

It is a natural bio-enhancer obtained from citrus fruits, especially in grapefruit. Naringin is responsible for the fruit's bitter taste. The 
chemical structure consist of a flavone-7-0-glycoside between the flavanone naringenin and the disaccharide neohesperidose [31].

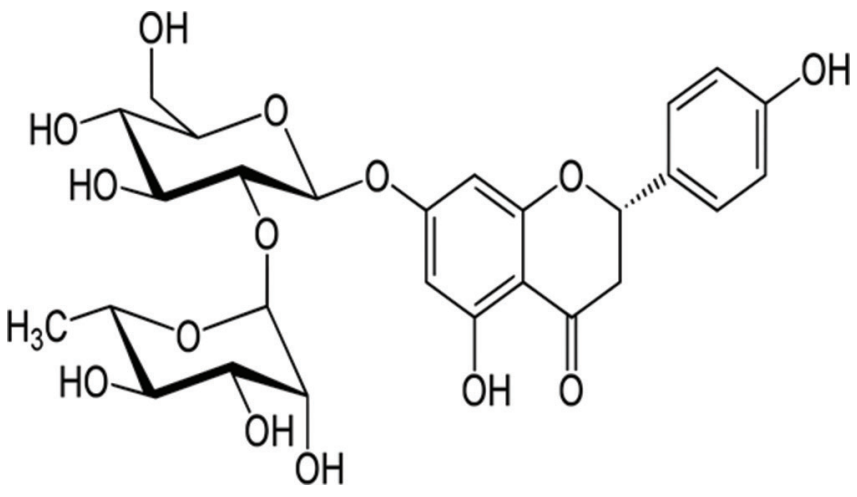

IUPAC name: 7-[[2- $O$-(6-Deoxy- $\alpha$-L-mannopyranosyl)- $\beta$-Dglucopyranosyl]oxy]-2,3-dihydro-5-hydroxy-2-(4-hydroxyphenyl)4H-1-benzopyran-4-one

The various pharmacological effects shown by naringin include antioxidant, blood lipid-lowering, and anticarcinogenic activities. In multiple studies done on rats its observed that naringin also inhibits CYP3A1/2 and P-glycoprotein. When naringin of doses 3.3 and 10.0 $\mathrm{mg} / \mathrm{kg}$ was given orally $30 \mathrm{~min}$ before the intravenous administration of $3 \mathrm{mg} / \mathrm{kg}$ dose of paclitaxel, a remarkable rise of $40.8 \%$ and $49.1 \%$ in AUC for both naringin doses, respectively, was reported after the intravenous administration of paclitaxel [31].

\section{Sinomenine}

Sinomenine is an alkaloid extracted from Sinomenium acutum Thunb.

Its structure and IUPAC [32].

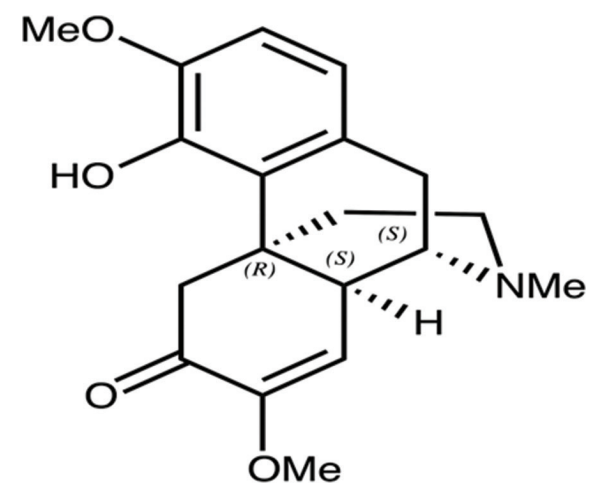

IUPAC name (9 $\alpha, 13 \alpha, 14 \alpha)$-4-Hydroxy-3, 7-dimethoxy-17 methyl-7, 8-didehydromorphinan-6-one

Paeoniflorin is a bioactive monoterpene glycoside, used widely to treat inflammation and arthritic conditions. The problem with paeoniflorin is that its absorption rate is weak, and hence bioavailability is low. Its bioavailability is around $3-4 \%$ when administered orally. When paeoniflorin and sinomenine are coadministered, the pharmacokinetic behaviors of paeoniflorin are altered dramatically in rats, which resulted in increased oral bioavailability of paeoniflorin by more than 12 times. The reason behind this enhanced bioavailability by sinomenine could be the decrease in the efflux transport of paeoniflorin by P-glycoprotein in the small intestine [33-35].

\section{Glycyrrhizin}

It is a triterpenoid saponin found in Glycyrrhiza glabra L. belonging to family Fabaceae). The chemical structure of glycyrrhizin with its IUPAC name.

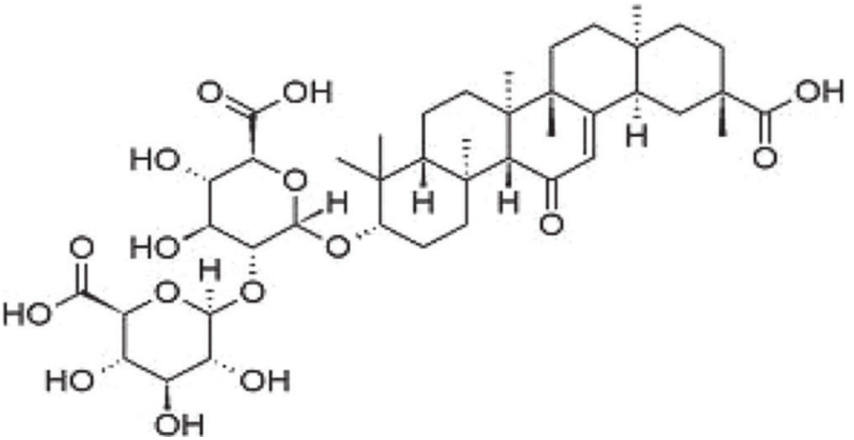

IUPAC $(3 \beta, 20 \beta)$-20-carboxy-11-oxo-30-norolean-12-en-3-yl 2-0- $\beta$-D-glucopyranuronosyl- $\alpha$-D-glucopyranosiduronic acid

Absorption enhancing activity by glycyrrhizin found more effective than caproic acid when both tested at the same concentration [36]. The absorption-increasing property in Caco-2 cell monolayer was found considerably more from sodium deoxycholate and dipotassiumglycyrrhizin treatment done simultaneously than sodium deoxycholate alone [37].

\section{Nitrile glycosides}

The biological source of nitrile glycosides and its derivatives consist of the pods of Moringa oleifera, belonging to family moringaceae. As observed in various studies, they do not have their drug activity but can promote and raise the biological activity, bioavailability of the drug uptake in combination therapy. The nitrile glycoside, like niaziridin, has enhanced the absorption of vitamins, nutrients, and various commonly used antibiotics such as ampicillin, rifampicin, and tetracycline . In a bioactivity test, the activity of ampicillin, rifampicin, and nalidixic acid against both Gram- positive and Gram-negative strains was notably improved, by the niaziridin-rich fraction of M. oleifera [38].

\section{Lysergol}

It is an alkaloid found in some species of fungi like ergot fungus and in the morning glory family of plants (Convolvulaceae), which include the hallucinogenic seeds of Rivea corymbosa, Argyreia nervosa, and Ipomoea violacea. As it is a derivative of dimethylergoline, also called clavine. The four-ring structure of lysergol and its IUPAC name.

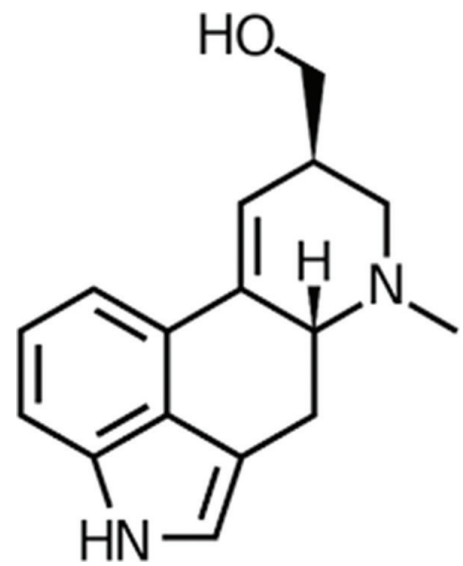

IUPAC name (7-Methyl-4,6,6a,7,8,9-hexahydro-indolo [4,3-fg] quinolin-9-yl)-methanol

It is an excellent herbal bio-enhancer, as it amplifies the killing activities of different antibiotics on bacteria [39].

\section{Allium sativum}

Allicin is the active bio-enhancer found in garlic. It enhances the fungicidal activity of amphotericin B against pathogenic fungi such as Candida albicans, Aspergillus fumigatus, and yeast (Saccharomyces 
cerevisiae) [40]. Allicin is an acyclic compound with a straight-chain having sulfur as its constituent.

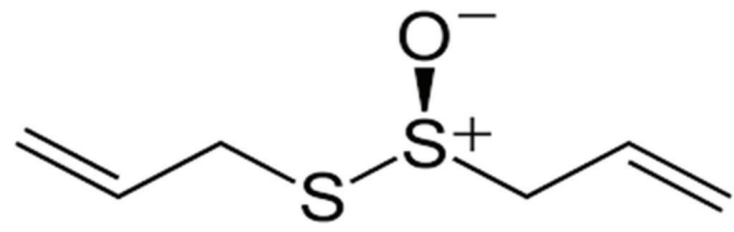

IUPAC $S$-Prop-2-en-1-yl prop-2-ene-1-sulfinothioate

\section{Piperine}

It is a well-known alkaloid obtained from $P$. nigrum or $P$. longum, whether stem, pods, or leaf parts. It has proved to be a milestone in the field of biopotentiation. It is authorized as safe by FDA [41]. It contains a cyclic six-membered secondary amine in its structure as follows.

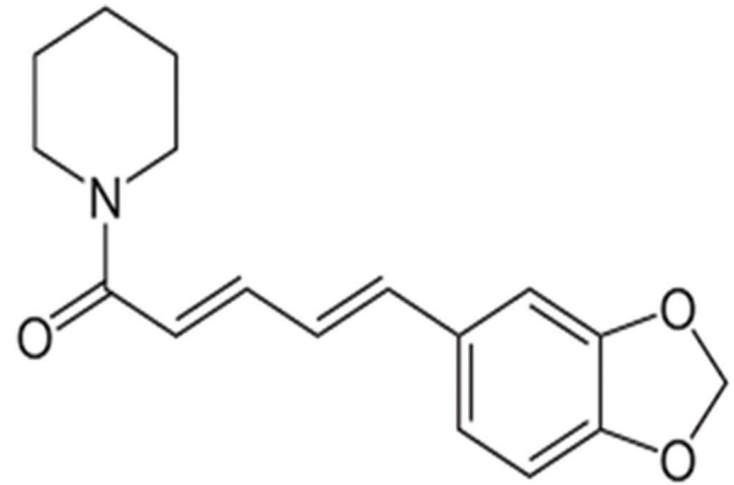

IUPAC name: (2E,4E)-5-(2H-1,3-Benzodioxol-5-yl)-1-(piperidin-1yl)penta-2,4-dien-1-one

\section{The use of piperine in different formulations \\ Metabolic enzymes}

Piperine has shown its effect on metabolic enzymes and degradation related enzymes both in vitro and in vivo. It has been proved as a nonspecific inhibitor of drug metabolism in different studies. There are various series of enzymes inhibited by piperine, mainly associated with P-GP and cytochrome P 450 families [15,42]. It also includes others such as:

a. Aryl hydrocarbon hydroxylase (of Microsomal enzyme system)

b. Ethyl morphine- $\mathrm{N}$ demethylase

c. 7-Ethoxycoumarin-0-de-ethylase

d. Uridine diphosphate glucose dehydrogenase

e. Uridine diphosphate glucose dehydrogenase

f. Uridine diphosphate glucuronyltransferase

g. 5-Lipoxegenase (h) Cyclo-oxygenase-I.

\section{Antitubercular and antileprotic drugs}

Bioenhancing property of piperine utilized first to treat tuberculosis in humans, for example, alongside Rifampin or Rifampicin (the medication of first-line therapy in tuberculosis and leprosy). It extend the bioavailability of rifampicin by about $60 \%$, and subsequently reduced the dose from 450 to $200 \mathrm{mg}$. Rifampin works by acting on RNA polymerase and inhibits the transcription of the polymerase in human cells, which is being catalyzed by Mycobacterium smegmatis. Piperine enhances this activity of rifampin by several folds against RNA polymerase Piperine also stimulates the coupling capacity of rifampin to RNA polymerase even in resistant strains $[43,44]$.

\section{Antibiotics}

There has been a considerable increment in the consumption of antibiotics and antimicrobials at a very high rate, which has caused most of the cases such as immune system resistance or addiction. Patients require a high dose of such drugs due to reduced GIT absorption, uptake by pathogens, and cells that have decreased due to resisting efflux pumps. The large part of the target dose remains as waste in body fluids having no remedial use but causing drug resistance and side effects or toxicity with time. In the studies done on rabbits, fluoroquinolones and piperine have shown raised bioavailability as piperine inhibits the P-glycoprotein efflux pump [45].

\section{Chemoprevention and immunomodulators}

Piperine decreases cytotoxicity by reducing aflatoxins, which causes cytotoxicity by inhibiting CYP-P450-mediated biological activation of mycotoxins into harmful ones [46]. It modifies the oxidative changes in cells by inhibiting the lipid peroxidation phenomena, resulting in free radicals scavenging activity [47]. This process diminishes the harm to DNA and DNA proteins. The antiapoptotic property of piperine is due to the induction of Heme-oxygenase-1. It contains the pentacyclic oxindole group in it, responsible for all these activities [48].

\section{Nutraceuticals}

It likewise enhances bioavailability and retention of nutrients by acting on the alimentary canal, acting as a nutritional bio-enhancer. During double-blind cross over studies, the increase in the concentration of vitamins against placebo by $50-60 \%$ utilizing herbal supplementation was revealed. The outcome from various studies expresses that it is because of the nonspecific mechanism and thermogenic properties of piperine $[12,49]$.

Other upgraded bioavailability showed by it of medications like Nevirapine, a potent non-nucleoside inhibitor of HIV-1 reverse transcriptase, utilized in blend with other antiretroviral agents for the treatment of HIV-1 infection.

\section{Herbs used as bioavailability enhancers Cuminum cyminum}

Natural bio-enhancer C. cyminum commonly called cumin is found as a little and meager yearly spice, grown extensively in South-East Europe and North Africa circumscribing the Mediterranean Sea. It is a powerful gastric energizer, useful in stomach protuberance and flatulence. It has curatively been used as an anti-diarrheal agent, galactagogue, diuretic, and helpful in hoarseness of voice. Bioefficacy enhancing activity of cumin is revealed toward various medications. Different volatile oils and flavonoids have shown bioavailability improving activity. For the most, luteolin has proved to be a robust P-glycoprotein inhibitor in the writing [50-52].

\section{Z. officinale}

Ginger is the rhizome of $Z$. officinale belonging to family Zingiberaceae, powerfully affects GIT mucous film. It manages the functions of intestine to ease absorption. $10-30 \mathrm{mg} / \mathrm{kg}$ body weight range of ginger acts as a bio-enhancer. Example of various antibiotics whose bioavailability rose by it includes, azithromycin (85.0\%), erythromycin (10.5\%), cephalexin (85.0\%), cefadroxil $(65.0 \%)$, amoxicillin $(90.0 \%)$, and cloxacillin $(90.0 \%)$ are expanded by it [53].

\section{Aloe vera}

It is dried juice collected by incision, from the bases of the leaves of various species of aloe, Aloe perryi, A. vera or Aloe barbadensis, and Aloe ferox, belonging to family Liliaceae. There are two different preparation of A. vera, that is, entire leaf extract and gel-filled inside, which showed the increased absorption of both the Vitamins $\mathrm{C}$ and E. Various studies concluded, $A$. vera as an exceptionally promising future nutritional herbal bio-enhancer [54].

\section{Turmeric}

It is a spice used for centuries in Ayurveda for therapeutic purposes and also in Indian kitchens for adding color and flavor to the food. It is called as Haldi in Hindi. It is derived from dried as well as fresh rhizomes of the plant known as Curcuma Longa, belonging to family 
Zingiberaceae. Turmeric contains a flavonoid called curcumin, which suppresses metabolizing enzymes like CYP3A4 in the liver. It is also capable of initiating an adjusting drug transporter P-gp; consequently increases the bioavailability of celiprolol and midazolam in rats. The bio-enhancing property of curcumin is analogous to piperine. Curcumin put down the UDP-glucuronyl transferase level in intestine and hepatic tissues. It likewise changes the physiological activity in the GIT promoting better absorption of drugs [55]

\section{Bioenhancers of non-herbal origin}

Capmul

Capmul MCM C10, which is a glyceryl monocaprate, is one of the greatly utilized bio-enhancers. Its production is from edible fats and oils which is commonly used in lip products. In a study did on rats of antibiotic ceftriaxone when co-administered with capmul, enhanced its bioavailability by $80 \%$ [17].

\section{Cow urine distillate}

It is more effective as bio-enhancer than cow urine. The potency of antimicrobial, antifungal, and anti-cancer drugs is enhanced by it. The US Patents (No. 6896907 and 6410059) has been granted to cow urine for its medicinal properties, especially as a bio-enhancer with antibiotics, antifungal, and anti-cancer drugs. The potency of paclitaxel, observed to increase against MCF-7, a human breast cancer cell line, in in vitro assays (US Patent No. 6410059) [56,57]. The cow urine distillate enhanced the rifampicin action by about 5-7 times against Escherichia coli and 3-11 times against Gram-positive bacteria. It most likely acts by improving the transport of antibiotics across the digestive tract membrane. The improvement in transport is roughly 2-7 folds. The gonadotropin-releasing hormone conjugate deleteriously affects the reproductive hormones and estrous cycle of female mice, and distillate of cow urine acts as a bio-enhancer in immunization efficacy adjust these impacts [58].

\section{Need for bioavailability enhancers}

Because of an expansion in the no. of medical advancement likewise, there is an increase in various side effects created by them. By the utilization of bio-enhancers, the dose can diminish to a great extent, which can assist to lessen the possibilities of side effects. Several plant extracts and phytoconstituents, even with incredible bioactivity in vitro, show less or no in vivo actions, because of their helpless lipid solubility or inappropriate atomic size or both, bringing about poor absorption, and poor bioavailability. It was found that when single constituents were confined from the plant extract, there is a loss of particular bio-activity. Sometimes certain parts of the multi-constituent plant extract are demolished in the gastric condition when taken orally. They lower the dose, abbreviate the treatment time frame, and accordingly diminish drug resistance issues. Because of the dose economy, they make treatment financially savvy; minimize drug toxicity, and unfavorable responses.

\section{Problems/disadvantages/hurdles with bio-enhancers}

As the bio-enhancers have a chemical entity in them, they can have their reactions as well, and when administered alongside other drugs, may end up in interactions and other side effects. However, a portion of the difficulties experienced have been solved by modifying the physicochemical characteristics of the nanomaterials to enhance properties such as high circulation within the blood, expanded functional surface area, and protection of the incorporated drug from degradation, the crossing of biological barriers, and site-specific targeting. Another test of innovative work in the development of herbal bio-enhancers is large scale production. There is consistently a requirement to scale up laboratory or pilot innovations for possible commercialization. Making the nano or microparticles and maintaining their size and also to convenience with the medications is likewise a significant issue [59].

Advances in natural bio-enhancers likewise give new difficulties to administrative control. There is an expanding need to have guidelines that would represent the physicochemical and pharmacokinetics of nano-drug products, which are not quite the same as traditional medication items. The United States' Food and Drug Administration and the European Medicines Evaluation Agency have taken the initiative to recognize some possible scientific and regulatory challenges [20].

\section{Relation of bioenhancers with ayurveda}

Present-day science is developing bio-enhancers as a new science for expanding the adequacy of medication, still this concept was started and was documented hundreds of years back and was utilized as a system of medicine. In Ayurveda, several herbs were used, such as P. longum, Z. officinale, and G. glabra having action as bio-enhancers and different strategies for bio-enhancing for centuries. There are various concepts and techniques in Ayurveda such as

- Yogavahi,

- Anupana,

- Bhaishajya Kala,

- Bhavana (trituration),

- Rasayana,

- Yoga (formulations), and

- Kalpanas (various dosage forms).

The different ideas of Purana Aushadhies (old drugs), the concept of activity increasing medications, and penetration enhancers had been used since ancient time in Ayurveda. Besides, Samshodhana (biopurification) can be considered for this idea. The definite investigation of these ideas clarifies the idea of bio-enhancers [60].

\section{Ideal property of bio-enhancers}

The ideal bio-enhancers need to be [61-73]

- Nontoxic, non-allergenic, and non-irritating,

- Produce own pharmacological effects,

- Rapid-acting with predictable and reproducible activity,

- Unidirectional in action,

- Compatible with other active pharmaceutical ingredients,

- Stable with time and environment,

- Easily formulated into a various dosage form, and

- Easily available and cost-effective.

\section{Recent advancement in bioenhancers}

Various formulations made by the advancements in bio-enhancers are as follows

- Quercetin liposome: It is a formulation with biological activity as an anti-oxidant, anti-cancer with the active ingredient quercetin. It can be prepared by the reverse evaporation technique. It has the benefits of reducing the dose, enhancing penetration in the bloodbrain barrier, given by the intranasal route [1].

- Liposome encapsulated silymarin: Silymarin is an active constituent that improves the bioavailability of formulation. It has hepatoprotective activity, given by the buccal route. Its preparation is also by reverse evaporation technique [64].

- Rutin-alginate chitosan microspheres: Its target is cerebrovascular system. The main component as rutin, it is given intravenously. Its formulation is by complex coacervation method [65].

- Zedoary oil microspheres: This formulation is hepatoprotective with the main ingredient as zedoary. The technique for its preparation is quasi emulsion solvent diffusion. It is a sustained release and is highly bioavailable with the oral route of administration [66].

- Triptolide nanoparticles: This formulation has anti-inflammatory activity with enhanced penetration of the drug through stratum corneum by hydration. The active ingredient is triptolide having a topical route of administration. The method of preparation is an emulsification ultrasound [67].

- Radix salvia miltiorrhiza nanoparticle: This formulation of radix salvia has biological activity in coronary heart disease, angina pectoris, and myocardial infarction tested in vitro. Preparation is through the spray drying technique [68].

- Capsaicin transferosomes: It is a topically applied formulation having analgesic activity. Capsaicin is its active ingredient with increased skin penetration [69]. 
- Colchicine transferosomes: This formulation tested in vitro for gout treatment having good skin penetration [70].

- Ginseng lipid-based system: It is a nutraceutical immune modulator having flavonoids as active constituent. It has oral route of administration and prepared by phospholipid complexation technique [71].

- Green tea lipid-based system: It is a nutraceutical with ginsenoside as the active ingredient, has antioxidant, and anti-cancer properties. Prepared by the phospholipid complexation technique [72].

Recent patents on herbal controlled release formulation [73]

\begin{tabular}{|c|c|c|}
\hline $\begin{array}{l}\text { Novel drug delivery } \\
\text { system }\end{array}$ & Active ingredient & US patent no. \\
\hline Nasal spray & Opioid analgesic and aloe & US 5948414 \\
\hline $\begin{array}{l}\text { Microencapsulated } \\
\text { and controlled } \\
\text { release formulation }\end{array}$ & Ginsenoside & US 6340478 B1 \\
\hline $\begin{array}{l}\text { Microencapsulated } \\
\text { formulation }\end{array}$ & Isoflavones & US $6890561 \mathrm{~B} 1$ \\
\hline $\begin{array}{l}\text { Transdermal } \\
\text { delivery system }\end{array}$ & $\begin{array}{l}\text { Alkaloids of aconitum } \\
\text { species }\end{array}$ & 896898 B1 \\
\hline Brain tonic & $\begin{array}{l}\text { Sesamum indicum oil and } \\
\text { Centella asiatica alcoholic } \\
\text { extract }\end{array}$ & $\begin{array}{l}\text { US patent } 2005 \text { / } \\
0142232 \mathrm{~A}\end{array}$ \\
\hline $\begin{array}{l}\text { Herbal tablet dosage } \\
\text { form }\end{array}$ & $\begin{array}{l}\text { Glycine max containing } 7 \mathrm{~s} \\
\text { globulin protein extract, } \\
\text { curcumin, Zingiber }\end{array}$ & $\begin{array}{l}\text { US patent } 2007 / \\
0042062 \mathrm{~A} 1\end{array}$ \\
\hline Transdermal patch & $\begin{array}{l}\text { Opioid analgesic } \\
\text { (phenanthrene) }\end{array}$ & $\begin{array}{l}\text { US patent } 2007 \text { / } \\
0077284 \mathrm{~A} 1\end{array}$ \\
\hline Microgranules & Flavonoids and terpenes & $\begin{array}{l}\text { US patent } \\
7569236132\end{array}$ \\
\hline
\end{tabular}

Employment of silver and gold nanoparticles by the use of plant extracts

There are many pharmaceutical uses of nanoparticles. When the silver nitrate solution is contacted with geranium (Pelargonium graveolens) leaf extract, a rapid reduction of the silver ions was observed [74]. The preparation used to reduce Ag+ ions to $\mathrm{Ag}$ is an extract produced by taking $20 \mathrm{~g}$ of chopped and washed geranium leaves with $100 \mathrm{~mL}$ of distilled water in a $500 \mathrm{~mL}$ Erlenmeyer flask. The suspension was boiling for $1 \mathrm{~min}$. A volume of $5 \mathrm{~mL}$ of pure broth added to $100 \mathrm{~mL}$ of $0.001 \mathrm{~mol} / \mathrm{L}$ aqueous solution of AgNO3. The ultraviolet (UV)-visible spectrum helps to estimate the bioreduction of the Ag+ ions of the solution.

With neem leaf extract, a competitive reduction of $\mathrm{Au} 3+$ and $\mathrm{Ag}+$ ions co-occur in solution. It has led to the synthesis of bimetallic $\mathrm{Au}$ core- Ag shell nanoparticles in solution [75]. Using the new sundried biomass of Cinnamomum camphora leaf silver nanoparticles ranging from 55 to $80 \mathrm{~nm}$ inside and triangular or spherical gold nanoparticles were fabricated. The preparation of gold nano triangles by leaf of camphor tree is done at ambient temperature firmly relied on the measure of dried biomass. This biomass offered adequate defensive biomolecules [76].

A process of applying A. vera leaf extract used for making gold nano triangles and spherical silver nanoparticles could be utilized. The kinetics is estimated by UV-visible absorption spectroscopy and transmission electron microscopy [70].

\section{Other recent advances}

- Ketoprofen-loaded solid lipid nanoparticles (SLNs) made from beeswax and carnauba wax was evaluated by Kheradmandnia et al. They discovered that the average particle size of medication loaded SLNs decline on blending with Tween 80 and egg lecithin also on expanding total concentration of surfactant. The ability of SLNs to incorporate a poorly water-soluble drug such as ketoprofen, revealed by high drug entrapment efficiency (EE) of 97\% [77].

- Curcuminoids- loaded SLNs are formulated and characterized by Tiyaboonchai et al. They noticed that lyophilized curcuminoids loaded SLNs showed bio-enhancement of up to $70 \%(\mathrm{w} / \mathrm{w})$ with spherical particles of mean particle size $450 \mathrm{~nm}$ and 0.4 as polydispersity index [78].

- Emodin-loaded SLNs (E-SLNs) preparation evaluation; characterization; and antitumor activity were studied by Wang and group. The investigation of physicochemical properties of the E-SLNs was by particle size analysis, zeta potential measurement, drug EE, stability, and in vitro drug release behavior. The medication liberated by E-SLNs last for $72 \mathrm{~h}$ and displayed a sustained profile, which made it a favorable oral drug delivery system [79].

- SLNs-coated Silk fibroin was also developed by an emulsification and solidification method using sodium lauryl sulfate (an anionic surfactant) as a stabilizer. Then, the SLN was covered with silk fibroin under an acidic condition by electrostatic interaction. The silk fibroin layer of nanoparticles contains positive charge; hence, it shows good interaction with oppositely charged skin cells, improving the permeability of skin [80].

- The cellular uptake of SLNs and cytotoxicity of encapsulated paclitaxel in A549 cancer cells were investigated by Yuan et al. The modified SLN with PEG and folate could upgrade the SLN cellular uptake and the cellular cytotoxicity of the medication that improves folate receptor mediated endocytosis [81].

- SLNs as the topical carrier for epidermal targeting of podophyllotoxin (P-SLN) were evaluated by Chen et al. [82].

- The potential use of SLNs in dermatology and cosmetics, incorporated in a hydrogel or o/w-cream was tested and its influence on drug penetration into porcine skin was given by Jenning and group [83].

- Piperine was found in both long pepper and black pepper as the potent bio-enhancer was studied by Singh et al. Piperines can improve the binding ability of rifampicin to RNA polymerase [84].

- Nanotechnology-based combination drug delivery to tumor tissues was reported by Parhi et al. It emerged as an effective for delivery of anticancer drugs [85].

- Rajendran et al. prepared the ethanolic extract of Ocimum sanctum, which was loaded inside the sodium alginate chitosan nanoparticles by cation induced controlled gellification method and finished on cotton fabric by pad dry cure method. This examination uncovered that the herb encapsulated nanoparticle could act as a biocontrol agent against microscopic organisms in fabrics [86].

\section{Future prospects}

Using the bio-enhancers, the dose requirement can be diminished, and the dangers of drug resistance and other side effects can be minimized. Many drugs are very useful but have great side effects and toxicity (chemotherapy drugs, e.g., taxol) by the use of bio-enhancers; their toxicity chances can reduce. As the dosage is reduced, prescription needed is less; hence, it is economically beneficial too. Hence, use of bio-enhancers in modern medicine can give rise to the development of safer, better, and effective medicine.

\section{CONCLUSION}

Bio-enhancer, which is a new and innovative concept, was well stated in Ayurveda and used for ages. The use of compounds derived from nature, having very less or no therapeutic activity but can help in improving the action of the active ingredient used along with them can be a very good step in medical field. The combination of new medical science technique and the concept of natural bio-enhancers, can lead to a perfect novel drug delivery system that can reduce drug cost by decreasing the required dose, reduced toxicity, lessen the side effects, and can provide various other advantages. This combined concept if will be used in our country having good knowledge of Ayurveda can lead to increased economy of the state, good position in the medical science concerning other countries and will be a better life-saving concept which can be easily made available for every section of society at a reasonable cost.

\section{CONFLICTS OF INTEREST}

None. 


\section{AUTHORS FUNDING}

None.

\section{AUTHORS CONTRIBUTION}

All authors have contributed equally.

\section{REFERENCES}

1. Kesarwani K, Gupta R. Bioavailability enhancers of herbal origin: An overview. Asian Pac J Trop Biomed 2013;3:253-66.

2. Atal CK. A breakthrough in drug bioavailability a clue from age old wisdom of Ayurveda. IDMA Bull 1979;10:483-4.

3. Johri RK, Zutshi U. An ayurvedic formulation "trikatu" and its constituents. J Ethnopharmacol 1992;37:85-91.

4. Lundin S, Artursson P. Absorption enhancers as an effective method in improving the intestinal absorption. Int J Pharm 1990;64:181-6.

5. Aungst BJ, Blake JA, Hussain MA. An in vitro evaluation of metabolism and poor membrane permeation impeding intestinal absorption of leucine enkephalin and methods to increase absorption. J Pharmacol Exp Ther 1991;259:139-45.

6. Schipper NG, Olsson S, Hoogstraate JA, Boer AG, Varum KM, Artursson P. Chitosan an absorption enhancers for poorly absorbable drugs: Influence of molecular weight and degree of acetylation on drug transport across human intestinal epithelial(caco-2) cells. Pharm Res 1996;113:1686-92

7. Liversidge GG, Cundy KC. Particle size reduction for improvement of oral bioavailability of hydrophobic drugs: I. Absolute oral bioavailability of nanocrystalline danazol in beagle dogs. Int J Pharm 1995;125:91-7.

8. Veiga F, Fernandes C, Teixeira F. Oral bioavailability and hypoglycaemic activity of tolbutamide/cyclodextrin inclusion complexes. Int J Pharm 2000;202:165-71.

9. Varma MV, Ashokraj Y, Dey CS, Panchagnula R. P-glycoprotein inhibitors and their screening: A perspective from bioavailability enhancement. Pharmacol Res 2003:48:347-59.

10. Annamalai AR, Manavalan R. Effects of trikatu and its individual components and piperine on gastrointerstinal tracts: Trikatua bioavailable enhancer. Indian Drugs 1989;27:595-604.

11. Bajad S, Bedi KL, Singla AK, Johri RK. Piperine inhibits gastric emptying and gastrointestinal transit in rats and mice. Planta Med 2001;67:176-9.

12. Majeed M, Badmaev V, Rajendran R. Use of Piperine to Increase the Bioavailability of Nutritional Compounds. United States: United States Patent, Number US5536506A; 1995.

13. Khajuria A, Thusu N, Zutshi U. Piperine modulates permeability characteristics of intestine by inducing alterations in membrane dynamics: Influence on brush border membrane fluidity, ultrastructure and enzyme kinetics. Phytomedicine 2002;9:224-31.

14. Reanmongkol W, Janthasoot W, Wattanatorn W, Upakorn PD, Chudapongse P. Effects of piperine on bioenergetics functions of isolated rat liver mitochondria. Biochem Pharmacol 1988;37:753-7.

15. Atal CK, Dubey RK, Singh J. Biochemical basis of enhanced drug bioavailability by piperine: Evidence that piperine is a potent inhibitor of drug metabolism. J Pharmacol Exp Ther 1985;232:258-62.

16. Johri RK, Thusu N, Khajuria A, Zutshi U. Piperine mediated changes in the permeability of rat intestinal epithelial cells: Status of gamma glutamyl transpeptidase activity, uptake of amino acids and lipid peroxidation. Biochem Pharmacol 1992;43:1401-7.

17. Cho SW, Lee JS, Choi SH. Enhanced oral bioavailability of poorly absorbed drugs. I. Screening of absorption carrier for the ceftriaxone complex. J Pharm Sci 2004;93:612-20.

18. Randhawa GK. Cow urine distillate as bioenhancer. J Ayurveda Integr Med 2010;1:240-1.

19. Chivte VK, Tiwari SV, Pratima A, Nikalge G. Bioenhancers: A brief review. Adv J Pharm Life Sci Res 2017;2:1-18.

20. Nijveldt RJ, Nood EV, van Hoorn DE, Boelens PG, Norren K, van Leeuwen PA. Flavonoids: A review of probable mechanisms of action and potential applications. Am J Clin Nutr 2001;74:418-25.

21. Hoi JS, Li X. Enhanced diltiazem bioavailability after oral administration of diltiazem with quercetin to rabbits. Int J Pharm 2005;297:1-8

22. Dupuy J, Larrieu G, Sutra JF, Lespine A, Alvinerie M. Enhancement of moxidectin bioavailability in lamb by a natural flavonoid: Quercetin. Vet Parasitol 2003;112:337-47.

23. Miniscalco A, Landahl J, Regardh CG, Edgar B, Eriksson UG. Inhibition of dihydropyridine in rat and human liver microsomes by flavonoids found in grapefruit juice. J Pharmacol Exp Ther 1992;261:1195-9.

24. Scambia G, Ranelletti FO, Panici PB, De Vincenzo R, Bonanno G, Ferrandina $\mathrm{G}$, et al. Quercetin potentiates the effect of adriamycin in a multidrug-resistant MCF-7 human breast-cancer cell line: P-glycoprotein as a possible target. Cancer Chemother Pharmacol 1994;34:459-64

25. Anup K, Sonia G, Swati K, Shrirang N, Waheed R, Vadim I, et al. The Studies on Bioenhancer Effect of Red Onions and Other Nutrients on the Absorption of Epigallocatechin Gallate from Green Tea Extract in Human Volunteers. Boston: $2^{\text {nd }}$ International Conference on Tumor Progression and Therapeutic Resistance Proceedings; 2005. p. 89.

26. Palle S, Neerati P. Enhancement of oral bioavailability of rivastigmine with quercetin nanoparticles by inhibiting CYP3A4 and esterases. Pharmacol Rep 2017;69:365-70.

27. Kurzer M, Xu X. Dietary phytoestrogens. Annu Rev Nutr 2003; $17: 353-81$

28. Sparreboom A, van Asperen J, Mayer U, Schinkel AH, Smit JW, Meijer DK, et al. Limited oral bioavailability and active epithelial excretion of paclitaxel (Taxol) caused by P-glycoprotein in the intestine. Proc Natl Acad Sci USA 1997:94:2031-5.

29. Doyle LA, Ross DD. Multidrug resistance mediated by the breast cancer resistance protein BCRP (ABCG2). Oncogene 2003;22:7340-58.

30. Huisman MT, Chhatta AA, Tellingen OV, Beijnen JH, Schinkel AH. MRP2 (ABCC2) transports taxanes and confers paclitaxel resistance and both processes are stimulated by probenecid. Int $\mathrm{J}$ Cancer 2005;116:824-9.

31. Zhang H, Wong CW, Coville PF, Wanwimolruk S. Effect of the grapefruit flavonoid naringin on pharmacokinetics of quinine in rats. Drug Metabol Drug Interact 2000;17:351-63.

32. Lim SC, Choi JS. Effects of naringin on the pharmacokinetics of intravenous paclitaxel in rats. Biopharm Drug Dispos 2006;27:443-7.

33. Cheng SS, Fu SX, Li YS, Wang NC. The pharmacology of sinomenine I: The analgesic and anti-phlogistic actions and acute toxicity. Acta Pharmacol Sin 1964:4:177-80.

34. Takeda S, Isono T, Wakui Y, Matsuzaki Y, Sasaki H, Amagaya S, et al. Absorption and excretion of paeoniflorin in rats. J Pharm Pharmacol 1995;47:1036-40.

35. Liu ZQ, Zhou H, Liu L, Jiang ZH, Wong YF, Xie Y, et al. Influence of co-administrated sinomenine on pharmacokinetic fate of paeoniflorin in unrestrained conscious rats. J Ethnopharmacol 2005;13:61-7.

36. Imai T, Sakai M, Ohtake H, Azuma H, Otagiri M. Absorption enhancing effect of glycyrrhizin induced in the presence of capric acid. Int J Pharm 2005;27:11-21

37. Sakai M, Imai T, Ohtake H, Azuma H, Otagiri M. Simultaneous use of sodium deoxycholate and dipotassium glycyrrhizinate enhances the cellular transport of poorly absorbed compounds across caco- 2 cell monolayers. J Pharm Pharmacol 1999;51:27-33

38. Khanuja SP, Arya JS, Tiruppadiripuliyur RS, Saikia D, Kaur H, Singh M. Nitrile Glycoside Useful as a Bioenhancer of Drugs and Nutrients, Process of Its Isolation From Moringa oleifera. United States: United States Patent 6; 2006.

39. Khanuja SP, Arya JS, Srivastava SK, Shasany AK, Kumar S, Ranganathan $\mathrm{T}$, et al. Antibiotic Pharmaceutical Composition with Lysergol as Bio-enhancer and Method of Treatment. United States: United States Patent, Number 20070060604; 2006.

40. Ogita A, Fujita K, Taniguchi M, Tanaka T. Enhancement of the fungicidal activity of amphotericin B by allicin, an allyl-sulfur compound from garlic, against the yeast Saccharomyces cerevisiae as a model system. Planta Med 2006;72:1247-50

41. Chavhan SA, Shinde SA, Gupta HN. Current trends on natural bioenhancers: A review. Int J Pharmacogn Chin Med 2018;2:000123.

42. Bhardwaj RK, Glaeser H, Becquemont L, Klotz U, Gupta SK, Fromm MF. Piperine, a major constituent of black pepper, inhibits human P-glycoprotein and CYP3A4. J Pharmacol Exp Ther 2002;302:645-50.

43. Balakrishnan V, Varma S, Chatterji D. Piperine augments transcription inhibitory activity of rifampicin by severalfold in Mycobacterium smegmatis. Curr Sci 2001;80:1302-5.

44. Kapil RS, Zutshi U, Bedi KL. Process of Preparation of Pharmaceutical Composition with Enhanced Activity for Treatment of Tuberculosis and Leprosy. United States: United States Patent Number, US005439891 A; 1995.

45. Khan IA, Mirza ZM, Kumar A, Verma V, Qazi GN. Piperine, a phytochemical potentiator of ciprofloxacin against Staphylococcus aureus. Antimicrob Agents Chemother 2006;50:810-2.

46. Reen RK, Wiebel FJ, Singh J. Piperine inhibits aflatoxin B1-induced cytotoxicity and geno toxicity in V79 Chinese hamster cells genetically 
engineered to express rat cytochrome P4502B1. J Ethnopharmacol 1997;58:165-73.

47. Selvendiran K, Singh JP, Krishnan KB, Sakthisekaran D. Cytoprotective effect of piperine against benzo[a]pyrene induced lung cancer with reference to lipid peroxidation and antioxidant system in albino mice. Fitoterapia 2003;74:109-15.

48. Choi BM, Kim SM, Park TK, Li G, Hong SJ, Park R, et al. Piperine protects cisplatin-induced apoptosis via heme oxygenase-1 induction in auditory cells. J Nutr Biochem 2007;18:615-22.

49. Badmaev V, Majeed M, Norkus EP. Piperine, an alkaloid derived from black pepper increases serum response of beta-carotene during 14-days of oral betacarotene supplementation. Nutr Res1999;19:381-8.

50. Zargari A. Medicinal Plants. Vol. 2. Tehran: Tehran University Press; 1989. p. 519-21.

51. Qazi GN, Bedi KL, Johri R, Tikoo MK, Tikoo AK, Sharma SC, et al. Bioavailability/Bioefficacy Enhancing Activity of Cuminum cyminum and Extracts and Fractions Thereof. United States: United States Patent 7514105; 2009.

52. Boumendjel A, Di Pietro A, Dumontet C, Barron D. Recent advances in the discovery of flavonoids and analogs with high-affinity binding to P-glycoprotein responsible for cancer cell multidrug resistance. Med Res Rev 2002;22:512-29.

53. Qazi GN, Tikoo GL, Gupta AK, Ganjoo SK, Gupta DK, Jaggi BS, et al. Bioavailability Enhancing Activity of Zingiber officinale and its Extracts/Fractions Thereof. European: European Patent Number EP 1465646; 2002.

54. Vinson JA, Kharrat HA, Andreoli L. Effect of Aloe vera preparations on the human bioavailability of vitamins $\mathrm{C}$ and $\mathrm{E}$. Phytomedicine 2005;12:760-5.

55. Hatcher H, Planalp R, Cho J, Torti FM, Torti SV. Curcumin: From ancient medicine to current clinical trials. Cell Mol Life Sci 2008;65:1631-52.

56. Available from: http://www.patentstorm.us/patents/6896907/ description.html. [Last accessed on 2010 Sep 02].

57. Ganaie JA, Shrivastava VK. Effects of gonadotropin releasing hormone conjugate immunization and bioenhancing role of kamdhenu ark on estrous cycle, serum estradiol and progesterone levels in female Mus musculus. Int J Reprod Biomed 2010;8:70-5.

58. Khan A, Srivastava V. Antitoxic and bioenhancing role of kamdhenu ark (cow urine distillate) on fertility rate of male mice (Mus musculus) affected by cadmium chloride toxicity. Int J Cow Sci 2005;1:43-6.

59. Wagner V, Dullaart A, Bock AK, Zweck A. The emerging nanomedicine landscape. Nat Biotechnol 2006;24:1211-7.

60. Singh S, Tripathi JS, Rai NP. An appraisal of the bioavailability enhancers in ayurveda in the light of recent pharmacological advances. Ayu 2016;37:3-10.

61. Raut SV, Nemade LS, Desai MT, Bonde SD, Dongare SU. Chemical penetration enhancers: For transdermal drug delivery systems. Int J Pharm Rev Res 2014;4:33-40.

62. Patil UK, Saraogi R. Natural products as potential drug permeation enhancer in transdermal drug delivery system. Arch Dermatol Res 2014;306:419-26.

63. Mirza ZM, Kumar A, Kalia NP, Zargar A, Khan IA. Piperine as an inhibitor of the MdeA efflux pump of Staphylococcus aureus. J Med Microbiol 2011;60:1472-8.

64. Ajazuddin SS, Saraf S. Applications of novel drug delivery system for herbal formulations. Nanomed Nanotechnol Biol Med 2008;4:70-8.

65. Samaligy MS, Afifi NN, Mahmoud EA. Evaluation of hybrid liposomes-encapsulated silymarin regarding physical stability and in vivo performance. Int J Pharm 2006;319:121-9.

66. Xiao L, Zhang YH, Xu JC, Jin XH. Preparation of floating rutinalginate-chitosan microcapsule. Chin Tradit Herb Drugs 2008;2:209-12.

67. You J, Cui F, Han X, Wang Y, Yang L, Yu YW, et al. Study of the preparation of sustained-release microspheres containing zedoary turmeric oil by the emulsion-solvent-diffusion method and evaluation of the self-emulsification and bioavailability of the oil. Colloids Surf B Biointerfaces 2006;48:35-41.

68. Mei Z, Chen H, Weng T, Yang Y, Yang X. Solid lipid nanoparticle and microemulsion for topical triptolide. Eur J Pharm Biopharm 2003:56:189-96.

69. Su YL, Fu ZY, Zhang JY, Wang WM, Wang H, Wang YC, et al. Microencapsulation of radix Salvia miltiorrhiza nanoparticles by spraydrying. Powder Technol 2008;184:114-21.

70. Xiao YL, Luo JB, Yan ZH, Rong HS, Huang WM. Preparation and in vitro and in vivo evaluations of topically applied capsaicin transferosomes. Yao Xeu Xeu Bao 2006;41:461-6.

71. Singh HP, Utreja P, Tiwary AK, Jain S. Elastic liposomal formulation for sustained delivery of colchicine: In vitro characterization and in vivo evaluation of anti-gout activity. AAPS J 2009;11:54-64.

72. Bhattacharya S, Ghosh A. Phytosomes: The emerging technology for enhancement of bioavailability of botanicals and nutraceuticals. Int J Health Res 2009;2:225-9.

73. Goyal A, Kumar S, Nagpal M, Singh I, Arora S. Potential of novel drug delivery systems for herbal drugs. Indian J Pharm Educ Res 2011;45:225-35.

74. Shankar SS, Rai A, Ahmad A, Sastry M. Rapid synthesis of Au, Ag and bimetallic Au core-Ag shell nanoparticles using neem (Azadirachta indica) leaf broth. J Colloid Interface Sci 2004;275:496-502.

75. Huang J, Li Q, Sun D, Lu Y, Su Y, Yang X, et al. Biosynthesis of silver and gold nanoparticles by novel sundried Cinnamomum canphora Leaf. Nanotechnology 2007;18:105104.

76. Chandra PS, Chaudhary M, Pasricha R, Ahmad A, Sastry M. Synthesis of gold nanotriangles and silver nanoparticles using Aloe vera plant extract. Biotechnol Prog 2006;22:577-83.

77. Kheradmandnia S, Farahani VE, Nosrati M, Atyabi F. Preparation and characterization of ketoprofen loaded solid lipid nanoparticles made from beeswax and carnauba wax. Nanomed Nanotechnol Biol Med 2010;6:753-9

78. Tiyaboonchai W, Tungpradit W, Plianbangchang P. Formulation and characterization of curcuminoids loaded solid lipid nanoparticles. Int $\mathrm{J}$ Pharm 2007;337:299-306.

79. Wang S, Chen T, Ruie C, Hu Y, Chen M, Wang Y. Emodin loaded solid lipid nanoparticles: Preparation, characterization and anti tumour activity studies. Int J Pharm 2012;430:238-46.

80. Kuchler S, Wolf BN, Heilmann S, Weindl G, Helfmann J, Yahya MM, et al. 3D wound healing model: Influence of morphine and solid lipid nanoparticles. J Biotechnol 2010;148:24-30.

81. Yuan H, Miao J, Du ZY, You J, Hu QF, Zeng S. Cellular uptake of solid lipid nanoparticles and cytotoxicity of encapsulated paclitaxel in A549 cancer cells. Int J Pharm 2008;348:137-45.

82. Chen H, Chang X, Du D, Liu W, Liu J, Weng T, et al. Podophyllotoxin loaded solid lipid nanoparticles for epidermal targeting. J Control Release 2006;110:296-306.

83. Jenning V, Gysler A, Korting SM, Gehla HS. Vitamin A loaded solid lipid nanoparticles for topical use: Occlusive properties and drug targeting to the upper skin. Eur J Pharm Biopharm 2000;49:211-8.

84. Bano G, Amla V, Raina RK, Zutshi U, Chopra CL. The effect of piperine on pharmacokinetics of phenytoin in healthy volunteers. Planta Med 1987:53:568-9.

85. Pahri P, Mohanty C, Sahoo SK. Nanotechnology based combinational drug delivery: An emerging approach for cancer drug therapy. Drug Discov Today 2012;17:1044-52.

86. Rajendran R, Radhai R, Kotresh TM, Csiszar E. Development of antimicrobial cotton fabrics using herb loaded nanoparticles. Carbohydr Polym 2013;91:613-7. 